\title{
Etnobiografias e descoberta de si: uma proposta da Antropologia da Educação para a formação de professores para a diversidade cultural
}

Ricardo Vieira*

\section{Resumo}

Consideramos a Antropologia da Educação como estudo dos processos educativos, seja na escola, na família, na rua ou na trajectória social dos indivíduos e seu papel na (re)construção das identidades pessoais. A partir de pesquisas realizadas em * Professor Coordenador Principal (Full Professor), CIID-IPLeiria e ESECSIPLeiria, Portugal. Portugal, procuro mostrar como as etnobiografias são um caminho privilegiado para entender as pessoas como resultado de uma bricolagem identitária e como são, também, meios de (auto) formação. Exploro as potencialidades das entrevistas etnobiográficas e grupais, na racionalização das experiências passadas, para a Antropologia da Educação na formação para a diversidade cultural.

\section{Palavras-chave}

identidades e histórias de vida; formação reflexiva; Antropologia da Educação; educação para a diversidade. 


\title{
Ethnobiographies and self-discovery: a proposal from educational anthropology for teachers' training in cultural diversity
}

\begin{abstract}
We consider the anthropology of education as the study of educational processes, whether at school, at home, on the street or in the social history of individuals and their role in the (re) construction of personal identities. Based on research conducted in Portugal, I try to show how ethnobiographical studies are a privileged way to understand people as a result of an identity bricolage and how they are also forms of (self) education. I explore the potential of ethnobiographic and group interviews for the rationalization of past experiences for educational anthropology within the training in cultural diversity.
\end{abstract}

Key words identities and life stories; reflective training; educational anthropology; training for cultural diversity. 


\section{A Antropologia da Educação: o estudo dos processos educativos}

Qualquer grupo social tem necessidade de transmitir conhecimento e saberes de modo a garantir a continuidade da sua cultura e promover a reprodução social (Iturra, 1996). Para tal, é preciso criar mecanismos que permitam essa reprodução. (Re)produção de conhecimentos e (re)produção de identidades (Vieira, 2011). 0 sistema educativo surge, nas sociedades ocidentais, com esse propósito. Mas o facto de se verificar que a cultura hegemónica destas sociedades dá maior importância ao conhecimento transmitido pelas escolas do que ao conhecimento transmitido e (re) apreendido noutros contextos culturais não significa que estes últimos não devam ser, também, estudados para compreendermos a construção das pessoas que vivem, cada vez mais, entre diversos mundos culturais que permeiam as próprias culturas pessoais, reconstruídas numa constante bricolagem identitária.

Consideramos, pois, a Antropologia da Educação como o estudo dos processos educativos ou, mesmo, o estudo de como os humanos aprendem, seja na escola, na família, na rua ou em toda a sua trajetória social, bem como, também, o estudo da constante e consequente (re)construção das identidades pessoais (Vieira, 2009).

A educação não remete apenas para a escola, como tantas vezes se esquece. Se o sentido corrente da palavra Educação e as próprias Ciências da Educação, tantas vezes, remetem o ensino e a aprendizagem para o domínio das aulas e das escolas, a verdade é que a Antropologia há muito faz notar que a escolarização dá a crianças e jovens apenas um pequeno contributo para a inculturação e a construção identitária. “Aprender, recordar, falar, imaginar, tudo isto é possibilitado através da construção numa cultura" (Bruner, 2000, p. 11). E a criança não cai de paraquedas na escola. A criança que chega à escola já tem todo um percurso de construção cultural que lhe dá um entendimento para a vida e uma epistemologia com a qual se senta como aluno nas cadeiras da escola (Iturra, 1990a, b).

Assim, a Antropologia da Educação que aqui preconizo não se resume, apenas, ao uso da etnografia em contextos educativos na escola, fora da escola, na família, nos tempos livres, etc. Com a Antropologia da Educação e suas metodologias hermenêuticas, pretendo compreender também as metamorfoses culturais que ocorrem na vida das pessoas, em consequência das convergências e divergências dos trajetos de vida face à(s) cultura(s) de onde partem. Assumo, pois, a ideia já não exclusiva de uma antropologia das culturas, mas, também, de uma antropologia das pessoas, elas pró- 
prias processos culturais em auto e heteroconstrução/reconstrução de si mesmas e da imagem que dão para os outros. Por isso dou ênfase, no final deste texto, ao estudo de alunos e professores através das suas biografias educativas para compreender como se tornaram naquilo que são (Vieira, 1999a, 1999b, 2009) e como contributo para uma formação reflexiva para a diversidade cultural (Vieira, 2011). Durante a sua história de vida e seu processo de socialização, que podem ser mais ou menos heterogéneos, conforme as esferas culturais, o indivíduo não desempenha um papel que lhe é absolutamente exterior. Nas sociedades modernas, é cada vez menor o peso da sociedade na determinação das identidades. A sociedade oferece apoios que facilitam o trabalho individual de encerramento em si, mas a auto e a heteroformação vão a par, e é, finalmente, o Homem que se constrói a si próprio: não é o produto do papel químico do pattern of culture da escola de cultura e personalidade (Vieira, 2009). Daí a importância da captação das subjetividades dos sujeitos estudados desse ponto de vista "émico", interior, que já propunha Malinowski.

Deste modo, a Antropologia da Educação aqui preconizada assenta num paradigma essencialmente interpretativo, semiológico e hermenêutico, em que a etnografia; a entrevista etnográfica e etnobiográfica; as (auto)biografias; a autorreflexão; os diários e as histórias de vida são vias fundamentais para compreender os processos educativos, de enculturação, aculturação e transmissão cultural, bem como a (re) construção identitária. Não se trata, pois, de procurar a causa das coisas educativas ou de fazer previsão ao modo do positivismo reducionista.

Jerome Bruner, que tem viajado da Psicologia cognitiva para a Psicologia cultural e que tem, assim, feito uma grande aproximação à Antropologia, a propósito de que estudar os processos educativos não é sinónimo de estudar o ensino e a aprendizagem na escola, numa obra dedicada à cultura da educação, refere que

[...] Se alguma coisa tem ficado cada vez mais claro nestes debates é que a educação não tem que ver propriamente com assuntos escolares convencionais, tais como currículo, níveis ou sistemas de prova. [...] a sua tese central (do livro Educação e Cultura) é que a cultura molda a mente, que ela nos apetrecha com os instrumentos de que nos servimos para construir não só os nossos mundos, mas também as nossas reais concepções sobre nós próprios e sobre as nossas faculdades [...]. Mas isto ultrapassa o domínio da escola. A educação não ocorre apenas nas aulas [...] (Bruner, 2000, p. 9-11). 
Também a Revista Europeia de Etnografia da Educação, um periódico da Sociedade Europeia de Etnografia da Educação - SEE -, fundada em 1999, no colóquio de Lecce (Itália), fala da passagem da formulação "etnografia escolar" para "etnografia da educação”, para dizer que não se limita às investigações na instituição escolar, mas abrange todo o campo educativo entendido com fenómeno social global.

Por isso falo da educação entre a escola e o lar. Por isso digo que o sucesso e o insucesso escolar são construídos socialmente (Iturra, 1990a, 1990b; Vieira, 1992). Por isso defendo a ideia da construção de professores capazes de agir interculturalmente e de construir pedagogias interculturais (Vieira, 1999a, 2011).

\section{Do estar dentro para compreender os processos educativos}

O uso do método etnográfico em contextos educativos leva a uma nova orientação epistemológica que ultrapassa as visões e as pesquisas sobre o insucesso e o sucesso escolar; e leva a uma nova atitude metodológica relativamente a quem investiga “factos educativos”, quer esta investigação seja por parte do antropólogo, quer pelo professor investigador que se preocupa em compreender os contextos de aprendizagem e de construção identitária dos seus alunos.

Como nos ensina Clifford Geertz (2001, p. 26):

Para descobrir quem as pessoas pensam que são, o que pensam que estão fazendo e com que finalidade pensam que o estão fazendo, é necessário adquirir uma familiaridade operacional com os conjuntos de significado no meio dos quais elas levam as suas vidas. Isso [...] Requer aprender como viver com eles, sendo de outro lugar e tendo um mundo próprio diferente.

Ao longo da história, as Ciências Humanas e, particularmente, a Antropologia, têm buscado quer a via do estudo da cultura e da sociedade como sistemas naturais, quer a consideração de tais esferas como sistemas simbólicos. No tocante à Antropologia e à Sociologia, a primeira das abordagens tem desembocado no positivismo. A segunda, por outro lado, tem-se inscrito fundamentalmente no casuísmo, na fenomenologia, na etnografia, no interpretativismo ou na hermenêutica.

Se bem que estas duas concepções de Antropologia tenham mantido adeptos, nenhuma delas conseguiu impor-se. Qualquer projecto de Antropolo- 
gia científica depara com uma dificuldade maior: é impossível descrever completamente um fenómeno cultural, umas eleições, uma missa ou um desafio de futebol, por exemplo, sem ter em conta a ideia que deles fazem aqueles que neles participam; ora, não se observam ideias, compreendem-se intuitivamente, e não se descrevem, interpretam-se. A descrição dos fenómenos naturais levanta, portanto, problemas epistemológicos sem equivalência nas ciências naturais. (Sperber, 1992, p. 24).

Toda a observação e toda a interpretação são seletivas. O que o etnógrafo consigna é apenas parte de um todo mais amplo. E o real de que ele fala é, em parte, o real que ele fabrica. Mas não o pode fabricar a partir de um conhecimento exterior. Se queremos compreender os processos educativos, como se aprende uma arte, uma profissão; como alguém se transformou naquilo que é hoje, urge fazê-lo a partir de dentro. Urge questionar a racionalidade do interior sem olhares de espanto exteriores. Urge "estar com”, “pensar com”, “sentir com”, “questionar com”. Urge uma nova etnografia da educação que rompa com a ideia clássica do distanciamento físico, em nome da objetividade. Para questionar a alteridade a partir dela, urge aprender com o outro antes de o questionar, e, muito menos, valorar. 0 distanciamento, esse, mantém-se, mas como atitude do investigador. 0 distanciamento, deste ponto de vista, é intelectual, não físico.

Por isso assumo a pesquisa etnográfica como algo próximo da bricolagem, no sentido da possibilidade da autonomia versus um conjunto de imposições dogmáticas. Trata-se de uma via distante da busca das regularidades da ciência positivista, em que “qualquer proposta de uma 'teoria geral' a respeito de qualquer coisa social soa cada vez mais vazia, e aquele que professa ter tal teoria é considerado megalomaníaco" (Geertz, 1999, p. 10).

De resto, o método científico passa a ser não o apregoado, no singular, como universal e único para as ciências experimentais, embora em nome de todas as ciências. Afinal, não temos objetos, mas, antes, sujeitos que, conjuntamente com o antropólogo, acedem a dimensões cognitivas, compreensões de si e dos outros, não passíveis de compreensão isoladamente, isto é, sem a presença do questionador. Por isso, a observação participante não é apenas participante. É participante mas, também, questionadora. 0 antropólogo aprende, na sua aproximação ao terreno, a fazer perguntas em contexto e, assim, vai realizando entrevistas "como conversas", de cariz 
etnográfico e etnobiográfico (Vieira, 2003, 2009), como exploro no ponto seguinte.

Os sujeitos entrevistados refletem, também eles, sobre as intenções do inquiridor e sobre si próprios. Não é apenas o investigador que investiga. É também o entrevistado que se pesquisa a si próprio e, em consequência, acede a uma dimensão reflexiva que não tinha ainda sido possível antes da interação. Por isso, as entrevistas etnobiográficas (Vieira, 2003), conducentes a trabalho com histórias de vida ou com narrativas (auto)biográficas, são um instrumento de pesquisa e, simultaneamente, de (trans)formação, de (auto)formação de quem é objeto de questionamento dentro da sua própria racionalidade (Josso, 2002).

\section{Entrevistas etnobiográficas e entrevistas em grupo no aprofundamento do conhecimento de si e dos outros}

É curioso como não se ouve falar, pelos analistas da investigação qualitativa ${ }^{1}$, dos trabalhos de Freud ou de Malinowski. Contudo, ambos os trabalhos se inserem facilmente neste tipo de abordagem. Um e outro buscam a via naturalista de pesquisa e assumem a interação com o objeto investigado como a via para aceder a uma nova dimensão de conhecimento: um novo conhecimento para o sujeito investigador e um novo conhecimento para o próprio objeto de estudo, tornado, também ele, sujeito de si próprio neste paradigma hermenêutico e interpretativo.

Uma das originalidades de Malinowski foi, justamente, ter combinado a observação participante, num prazo longo, com a entrevista, no intuito de identificar aspetos da visão do mundo dos habitantes das ilhas Trobriand que eles próprios eram incapazes de expressar verbalmente, por se tratar de crenças muito habituais para os membros do povo. Nesta linha, procuro, nos extratos de entrevistas que deixo adiante, mostrar como há um aceder do entrevistado à sua própria racionalidade; uma "descoberta" dos seus gostos e da razão pelo interesse do envolvimento; e empatia entre professor e aluno, isto a propósito duma investigação que realizei em Portugal sobre histórias de vida e identidades de professores. Surge uma lógica de $1 e 1=3$, já que é a presença da interação entre sujeito investigador e objeto investigado, também ele tornado sujeito de autorreflexão, que permite o surgir duma nova dimensão, de novos sentidos, duma terceira cultura (Vieira, 1999b).

1. Nas palavras dos que processam esta via. De facto, como já fiz notar (Vieira, 1999a) considero-a demasiado pobre para ser tomada como paradigma investigativo. Claro que a invenção dessa alternativa tem raízes históricas e como tal tem que ser compreendida. Quanto a mim, prefiro reservar o quantitativo e o qualitativo para as técnicas em si, de recolha e de tratamento, que até podem estar ou não ao serviço de um ou outro(s) paradigma(s) de investigação e não para caracterizar a falsa dicotomia dos modelos qualitativo e quantitativo de pesquisa. 
De facto, entrevistado e entrevistador alcançam dimensões do pensamento que não são passíveis de equacionar numa simples aritmética tipo $1+1=2$. 0 resultado é possivelmente melhor traduzido por um "três", símbolo da criatividade, do novo, pois contém uma descoberta e uma racionalização que resultam da materialização da interação entre, pelo menos, dois sujeitos.

Elsa Santos - Uma das coisas que me dava mais prazer era, na altura da primavera, assim maio,... pedir à minha mãe que me arranjasse um ramo de flores para ir levar à minha professora. Recordo-me perfeitamente de levar um grande ramo de flores e, várias vezes, um ramo de gipsófilas com rosas ou cravos pelo meio. Para mim, entrar na casa dela era sei lá o quê. E porque realmente eu gostava tanto, para mim era um prémio tão grande ir visitar a minha professora, ir-lhe levar um ramo de flores, ir a casa dela. Lanchar em casa da minha professora era uma coisa tão importante, que eu passei (agora que estou a pensar no assunto, penso que talvez isso tenha a ver com o hábito que tenho de levar os alunos a minha casa) a fazer o mesmo.

Investigador - E era também a sua professora que a convidava...?

E.S. - Sim...! Muitas vezes ela convidava, outras vezes era eu que ia lá oferecer-lhe um ramo. E, quando eu ia oferecer-lhe um ramo, ela convidava-me sempre para lanchar. Sentava-me lá, ela ficava comigo, eu sentia-me gloriosa, nem sei explicar, sei que era um empenho muito grande. Então eu dizia à minha mãe que queria ir muito bonita quando ia a casa dela. Era uma euforia para mim ir a casa da minha professora.

Inv. - Talvez a Elsa tenha então percebido a importância, para uma criança, de ver um relacionamento sadio entre os pais e os professores, essa mesma ligação que hoje procura fazer...?!

E.S. - Exatamente! Por isso mesmo, eu sempre também trouxe a minha casa alunos meus. E agora que estou a pensar nesse meu passado, talvez por isso eu tenha sempre defendido isso. Aqui na cidade talvez não tenha esse mesmo valor; mas nas aldeias, onde as pessoas veem a professora assim como sei 
lá o quê, o facto de os alunos irem a casa da professora conviver, é muito importante para as crianças. [...] agora é que eu penso porque sou assim, pensando como é que eu me sentia quando ia a casa da minha professora.

Os exemplos para mostrar como os sujeitos entrevistados se redescobrem, racionalizam experiências passadas, pela possibilidade de terem alguém que os ouça e os questione a partir das suas próprias lógicas e contextos (Nóvoa, 1992) poderiam ser imensos. Mas não é, de facto, o objetivo central deste texto. A ideia, neste tópico, é explicar a noção de entrevista etnográfica e etnobiográfica (quando o questionamento, hétero e auto, parte da biografia dos sujeitos), começando com exemplos práticos; neste caso, extratos de entrevistas com professores.

Nesse contexto, e de acordo também com Jean Poirier, Clapier-Valladon e Raybaut (1999), na orientação etnobiográfica, a história de vida é o ponto de partida para a compreensão do sujeito, a partir de uma análise extensiva a todas as dimensões da sua existência: "A etnobiografia é uma biografia sociocultural do ser colectivo de que o narrador se limita a ser uma das componentes" (Poirier; Clapier-Valladon; Raybaut, 1999, p. 40). Mais do que conhecer apenas a vida individual do informante, a etnobiografia ambiciona a compreensão do conhecimento que esse tem acerca dos modos culturais de funcionamento que o envolvem. Para tal, socorre-se, frequentemente, da entrevista biográfica, ou em profundidade, como instrumento metodológico privilegiado para compreender, por meio do trabalho etnográfico, a narrativa do universo de estudo, apelidada, também, de matéria-prima (Poirier; Clapier-Valladon; Raybaut, 1999, p. 39), que encontra, na história de vida, uma forma de perceber os modos subjetivos de intersecção entre o individual e o social.

Nas pesquisas que temos desenvolvido em Antropologia da Educação, temos investido em entrevistas de carácter etnobiográfico que nos têm permitido conhecer o domínio da intersubjetividade dos sujeitos. 0 trabalho de interação entre o investigador e o entrevistado, no seu próprio ambiente, surge como um caminho metodológico profícuo para compreender as transformações identitárias que a aprendizagem de conhecimentos e culturas por parte destes sujeitos produzem, no seu próprio mundo subjetivo e reflexivo, registado nas suas próprias falas. Assim, a entrevista em profundidade ${ }^{2}$ possibilita a recolha de material autobiográfico que nos é apresentado nas próprias palavras dos sujeitos

2. A entrevista em profundidade é aqui designada de etnobiográfica, pelo facto de a conversa entre investigador e investigado ter como objetivo a produção de uma narrativa biográfica. 
estudados, por meio da sua narrativa, em que descrevem e falam das suas vidas, oferecendo um testemunho único, permitindo a compreensão das suas representações, das suas formas de agir, dos incidentes (Kelchtermans, 1995) e dos marcos formativos nos seus percursos de vida.

Como instrumento metodológico, a entrevista etnobiográfica tem assumido, na minha investigação em Antropologia da Educação, duas formas distintas, mas também complementares: a individual e a grupal. Para compreendermos o peso da aprendizagem dita não formal e a subjetividade na construção do self pessoal e profissional, a entrevista etnográfica e etnobiográfica individual tem sido usada enquanto opção metodológica para as primeiras desocultações de incidentes críticos (Josso, 2002), modelos e pessoas considerados, pelo próprio entrevistado, enquanto agentes formativos e transformativos de si próprio. A entrevista grupal, focus-group na denominação inglesa, tem constituído, dentro do mesmo paradigma metodológico, uma importante técnica de complementaridade da abordagem individual.

Na sequência das entrevistas etnobiográficas individuais, o focus-group pode potenciar maior reflexividade pela oportunidade do mútuo questionamento que resulta do diálogo, reflexão ente vários sujeitos que pensam aprendizagens comuns, profissões comuns ou percursos sociais e de aprendizagens semelhantes.

\section{Interculturalidade, (auto)biografia como (re)descoberta de si e (trans)formação para a educação para a diversidade cultural}

A reflexão intercultural tem estado muito ligada aos problemas das migrações, às questões do ensino para imigrantes, à problemática dos trabalhadores estrangeiros, etc. (Camilleri; Cohen-Emerique, 1989). Mas o intercultural não se reduz às relações internacionais e interétnicas (Gusmão, 2004). Nas minhas pesquisas no âmbito da Antropologia da Educação, tenho procurado frisar outra dimensão da reflexão sobre o intercultural. Agora é sobre o contacto interpessoal, que é sempre intercultural, na sala de aulas - onde se constata também a multiculturalidade - e dos sujeitos aí presentes, com experiências, trajetórias, pensamentos, culturas pessoais e grupais, práticas e representações sociais próprios, que talvez interesse mais refletir na parte final deste texto.

No contacto intercultural, o que se comunica não são verdadeiramente as identidades grupais, as culturais nacionais ou locais mas, antes, as pessoas portadoras duma identidade pessoal, dinâmica, e sempre em gerúndio (Vieira, 2009), ela própria 
multicultural. Até numa visita de estudo da turma a determinado contexto, meio, exposição, ambiente, há sempre diligências pessoais que se podem revestir de aquisições de saberes, descoberta de tradições, paisagens, etc. Mas também se põem em contacto diferentes modos de vida, maneiras de pensar e de sentir próprios de grupos e das pessoas elas mesmas, num processo de interculturalidade.

A heterogeneidade cultural dos grupos é interiorizada, incorporada, de modo idiossincrático, por parte de cada aluno nesses encontros. Cabe ao professor desempenhar o papel de mediador intercultural (Vieira, 2011) e ajudar o aluno a (re)construir o seu eu intercultural, sem ambiguidades, sem grandes conflitos interiores ou receio de receber da alteridade para si. Como nos deixou bem claro Saint-Exupery, "Sou um pouco de todos que conheci, um pouco dos lugares que fui, um pouco das saudades que deixei e sou muito das coisas que gostei [...]". Mas, por vezes, num mundo que continua a pensar, a ver e a avaliar em preto e branco, de acordo com lógicas binárias e monistas (Vieira, 2009), não é fácil que cada um de nós assuma a multiculturalidade em si, a mestiçagem de si (Vieira, 2011). Aí, o papel do professor, também ele como investigador e etnógrafo da sua própria escola e turma, como antropólogo dos seus alunos, como contributo para a construção também de crianças interculturais, que podendo ser diferentes, possam, no entanto, comunicar-se. Daí que o professor deva interiorizar a mensagem da Antropologia da Educação, até ao ponto de sentir-se, ele mesmo, um antropólogo. Mas isso exige uma preparação antropológica dos professores, na formação inicial e na formação contínua. Não basta, não é suficiente uma relação professor-aluno empática. É preciso tirar partido da diversidade de contextos, para construir práticas pedagógicas interculturais, pois "a pedagogia intercultural permite sair da alternativa binária e demasiado simplista: novos objetos, novas didáticas" (Abdallah-Pretceille, 1990, p. 215-216).

Com vista a esta prática, qualquer professor deve começar por dar um primeiro passo para o desenvolvimento do seu eu pessoal e profissional. "Os professores precisam de ter um sentido muito claro da sua própria identidade étnica e cultural, para poderem compreender a dos seus alunos e respectivas famílias” (Zeichner, 1993, p. 89-90) e precisam melhorar os seus conhecimentos e atitudes em relação às diferentes características socioculturais dos seus alunos. Se não têm competências interculturais, há que procurar vias de as desenvolver, como é o caso do caminho que tenho proposto com o trabalho (auto)biográfico do próprio docente e dos seus alunos, para potenciar o pensar a aprendizagem do ponto de vista de quem aprende: 
A nossa questão central de investigação é a seguinte: o que é a formação do ponto de vista do aprendente? $0 u$, para sermos mais claros, quais são os processos que caracterizam a formação de um individuo, de uma singularidade, no que ela tem de semelhanças com outras, ainda que seja irredutível? Conhecendo o que é a educação enquanto acção de um colectivo sobre o indivíduo, procuramos conhecer o que é a formação enquanto actividade de um indivíduo em relação consigo próprio, com o seu meio humano e natural no seu percurso de vida. (Josso, 2002, p. 160).

É importante que cada profissional social, da educação ou não, tenha um conhecimento comparativo para além das circunstâncias imediatas do seu meio local. Há professores cuja trajetória social lhes deu esse treino de refletir as ações, de pensar o que se está a fazer, e por que se faz assim, e, no tocante aos outros, de procurar entender o seu entendimento. São pessoas que, no quotidiano, acabam por refletir a todo o momento e pôr, assim, em prática a sua metacognição. Surge então, por continuidade, um conhecimento comparativo dos diferentes meios sociais por parte deste tipo de sujeitos.

Por outro lado, também, há, assim, uma melhoria qualitativa do seu próprio conhecimento e do entendimento das suas ações e de seus saberes locais, pois o considerar das relações entre um determinado contexto e o seu ambiente social mais amplo ajuda a esclarecer o que se passa no próprio contexto. E comparar-se com o outro, que faz de modo diferente, implica, em primeiro lugar, conhecer-se a si próprio, tornar visíveis as suas práticas e representações sociais correlacionadas com a sua própria biografia, que suporta tais atitudes e condutas. Depois, em segundo lugar, implica contactar com a alteridade e perceber as alternativas à monoculturalidade, porventura do seu eu profissional. À partida, o docente, e não só, cai, não raras vezes, na tentação de considerar o que sucede habitualmente na sua vida quotidiana como o modo que as coisas, as práticas e as ideias efetivamente devem assumir para sempre e em todos os espaços. É o etnocentrismo, comum a todos os mortais e a todas as culturas, que urge ser relativizado. E, por isso, urge pensar, a este propósito, no papel da Antropologia da Educação na formação inicial, mas, também, na formação contínua, sempre, e não apenas para a adequação a uma reforma que se impõe normativamente. E importa pensar numa nova forma de fazer formação contínua, uma forma baseada essencialmente na reflexividade e na investigação: na investigação, 
por exemplo, das histórias de vida dos alunos que se têm, da própria autobiografia do docente e dos colegas, para se saber quem se é, quem se quer ser e como e quem são os outros. Enfim, uma formação contínua muito baseada, também, na reflexão autobiográfica. Perrenoud (1993, p. 35) refere que a mudança de práticas passa justamente por essa transformação do habitus, a que junta "a disponibilização de modelos de acção [...]”, já que a prática pedagógica "nunca é mera concretização de receitas, modelos didácticos, esquemas conscientes de acção”.

É partindo deste pressuposto que também Gaston Pineau (1990, p. 98) considera a reflexão sobre a história de vida como caminho fundamental para operar mudanças nas representações e nas práticas dos professores:

Fazer a sua história de vida é então menos recordar que acontecer. É apoiar-se sobre o passado para dele descolar e entrar nos movimentos plenos de contradições de começar a ser, utilizando-as de forma motriz.

A prática de confrontar a atividade das aulas da "nossa escola" com as de outras escolas, de outras sociedades contemporâneas, ou mesmo do passado, ou, ainda, mesmo com outros contextos institucionais, de fazer uma releitura da experiência (Huberman, 1983) serve para ampliar a visão da gama de possibilidades existentes quanto à eficácia da organização do ensino e aprendizagem nos vários grupos humanos.

À medida que se aprende mais acerca do mundo exterior, vai-se aprendendo mais acerca de nós mesmos. Preparar para educar na e para a diversidade implica o conhecimento e a (re)descoberta de si e do diálogo da própria multiculturalidade no eu pessoal e profissional. 


\section{Referências bibliográficas}

ABDALLAH-PRETCEILLE, M. Vers une pedagogie interculturelle. Paris: INRP, 1990.

BRUNER, J. Cultura e Educação. Lisboa: Edições 70, 2000.

CAMILLERI, C.; COHEN-EMERIQUE, M. (Dir.). Chocs des cultures: concepts et enjeux pratiques. Paris: L' Harmattan, 1989.

GEERTZ, C. Nova luz sobre a Antropologia. Rio de Janeiro: Jorge Zahar, 2001.

GEERTZ, C. O saber local: novos ensaios em Antropologia Interpretativa. Petrópolis: Vozes, 1999.

GUSMÃO, N. M. M. Os filhos da África em Portugal - Antropologia, multiculturalidade e educação. Lisboa: Imprensa de Ciências Sociais, 2004.

HUBERMAN, A. M. Comment s'oppèrent les changements en éducation: contribution à l'étude de l'innovation. Lausanne: Unesco, 1983.

ITURRA, R. A construção social do insucesso escolar. Lisboa: Escher, 1990 .

ITURRA, R. Fugirás à escola para trabalhar a terra: ensaios de Antropologia Social sobre o insucesso escolar. Lisboa: Escher, 199ob.

ITURRA, R. (Org.). O saber das crianças. Setúbal: ICE, 1996.

JOSSO, M. C. Experiências de vida e formação. Lisboa: Educa, 2002.

KELCHTERMANS, G. A utilização de biografias na formação de professores. Aprender

- Revista da Escola Superior de Educação de Portalegre, Portugal, n. 18, p. 5-20, 1995.

NÓVOA, A. (Org.). Vidas de professores. Porto: Porto Editora, 1992.

PERRENOUD, P. Práticas pedagógicas, profissão docente e formação. Lisboa: D. Quixote, 1993.

PINEAU, G. Les histoires de vie en formation: un mouvement socio-educatif. Le Groupe Familiale, Paris, n. 126, p. 26-35, 1990.

POIRIER, J.; CLAPIER-VALLADON, S.; RAYBAUT, P. Histórias de vida: teoria e prática. Lisboa: Celta, 1999.

SPERBER, D. O saber dos antropólogos. Lisboa: Edições 70, 1992.

VIEIRA, R. Educação e diversidade cultural: notas de Antropologia da Educação. Porto: Afrontamento, 2011.

VIEIRA, R. Entre a escola e o lar. Lisboa: Escher, 1992.

VIEIRA, R. Histórias de vida e identidades: professores e interculturalidade. Porto: Afrontamento, 1999a. 
VIEIRA, R. Identidades pessoais: interacções, campos de possibilidade e metamorfoses culturais. Lisboa: Colibri, 2009.

VIEIRA, R. Ser igual ser diferente: encruzilhadas da identidade. Porto: Profedições, 1999b.

VIEIRA, R. Vidas revividas: etnografia, biografias e a descoberta de novos sentidos. In: CARIA, T. (Org.) Metodologias etnográficas em Ciências Sociais. Porto: Afrontamento, 2003. p. 77-96.

ZEICHNER, K. M. A formação reflexiva de professores: ideias e práticas. Lisboa: Educa, 1993.

Submetido à publicação em 10 de janeiro de 2013.

Aprovado em 08 de março de 2013. 